\title{
Prevalence of Rumen and Reticulum Trematodes in The Goat Slaughtered at Pegirian Surabaya Slaughter House using Digestive Surgery Method
}

\section{Prevalensi Cacing Trematoda Rumen dan Retikulum pada Kambing yang dipotong di Rumah Potong Hewan Pegirian Surabaya dengan Metode Bedah Saluran Pencernaan}

\author{
${ }^{1)}$ Novia Intan Kurnia, ${ }^{2)}$ Setiawan Koesdarto, ${ }^{3)}$ Herry Agoes Hermadi, ${ }^{2)}$ Kusnoto, ${ }^{4}$ Hardany \\ Primarizky, ${ }^{2)}$ Agus Sunarso \\ ${ }^{1)}$ Student, Faculty of Veterinary Medicine, Universitas Airlangga \\ ${ }^{2)}$ Department of Veterinary Parasitology, Faculty of Veterinary Medicine, Universitas Airlangga \\ 3) Department of Veterinary Reproduction, Faculty of Veterinary Medicine, Universitas Airlangga \\ ${ }^{4)}$ Department of Veterinary Clinic, Faculty of Veterinary Medicine, Universitas Airlangga \\ Received: 05-08-2019, Accepted: 12-08-2019, Published Online: 16-o8-2019
}

\begin{abstract}
The purpose of this study was to determine the kind of trematodes which infected the rumen and reticulum of goat slaughtered at RPH Pegirian Surabaya using digestive surgery method, and determine the prevalence result. 36 samples of rumen and reticulum were collected from RPH Pegirian from September - November 2017 then using digestive surgery to obtain fresh adult worms, afterwards using the Semichen-Acetic Carmine staining method to makes the object easy to identifying. The results showed that species was found on goat was Paramphistomum cervi and Cotylophoron cotylophorum, in the Paramphistomum cervi are several characters wich is oral sucker, genital pore, uterus, testis, ventral sucker and in Cotylophoron cotylophorum contain oral sucker, branched oesophagus, uterus, vitelin glands, testes, posterior sucker. 3 rumen positive trematodosis with prevalence of $8.33 \%$ Chi-square statistic test ( $\mathrm{p}>0.05)$ showed no effect between goat species and Trematodosis prevalence, 20 kacang goat and 16 peranakan etawa goat found 2 positive kacang goat $(10 \%)$ and 1 peranakan etawa goat positive $(6.25 \%)$.
\end{abstract}

Keywords : Prevalence, Trematoda, Goat and Slaughtered House.

\section{Pendahuluan}

Populasi ternak kambing pada tahun 2014 diperkirakan 17,90 juta ekor dan pertumbuhan populasi kambing dari tahun 2012 ke 2013 sebesar 5,36\% (Ditjenak, 2014). Rumah Potong Hewan Pegirian Surabaya, merupakan tempat pemotongan hewan terutama ternak kambing di Kota Surabaya. Pemeriksaan status kesehatan kambing di RPH Pegirian Surabaya hanya terbatas pada kesehatan fisik. Mengingat pentingnya mengetahui tentang penyakit cacingan dan kurangnya data prevalensi trematodosis pada rumen dan retikulum kambing.

Penyakit parasitik pada ternak merupakan salah satu faktor yang dapat menurunkan produktivitas ternak. Berbagai penyakit cacingan yang menyerang kambing salah satunya adalah Trematodosis. Penyakit parasit yang sangat merugikan adalah penyakit yang disebabkan oleh parasit cacing trematoda yang dapat menginfeksi rumen dan retikulum kambing. Infeksi cacing trematoda dapat menyebabkan reaksi keradangan dan penebalan dinding mukosa. Pada cacing trematoda dewasa kurang patogen tetapi jika dalam jumlah besar bisa menyebabkan pelepasan papilla pada rumen (Kusumamihardja, 1995; Koesdarto dkk., 2007).

Ternak yang terinfeksi cacing trematoda biasanya mengalami kekurusan, pertumbuhan terhambat, penurunan produksi daging, penurunan daya tahan tubuh terhadap serangan penyakit lain dan pada infeksi yang berat dapat menimbulkan kematian (Khan dkk., 2008). Terdapat 3 spesies cacing yang menginfeksi rumen dan retikulum kambing yaitu $P$. cervi, $C$. cotylophorum, dan Gastrothylax crumenifer.

Kejadian Paramphistomiasis menurut data yang dilaporkan oleh Shabih di India (2006) menginfeksi sebesar 5,77\% kemudian kejadian juga terjadi di Nigeria pada tahun 2007 (Abunza dkk., 2008) sebesar 6, 7\% Tahun 2010 kejadian Paramphistomiasis sebesar 2,6\% yang dilaporkan di Bangladesh oleh Karim dkk., (2014). 
Cacing yang menginfeksi rumen bersifat endemik, tindakan pencegahan adalah suatu keharusan untuk mengurangi populasi siput, infeksi padang rumput pada stadium infektif. Inang perantara cacing trematoda adalah siput yang hidup di air (misalnya sungai, danau, kolam, rawa, saluran irigasi, parit, kolam, lubang berair, genangan air, dll.). Menjaga padang rumput tetap kering, baik untuk mengurangi populasi siput, atau untuk mempersingkat kelangsungan hidup metaserkaria (Junquera, 2017).

Berdasarkan latar belakang tersebut maka perlu dilakukan penelitian tentang prevalensi penyakit cacing yang disebabkan oleh cacing trematode untuk menentukan apa yang dilakukan pengendalian Trematodosis dan minimnya data mengenai prevalensi Trematodosis pada rumen dan retikulum kambing yang dipotong di RPH Pegirian Surabaya menggunakan metode bedah saluran pencernaan. Dengan mengetahui data yang diperoleh, diharapkan dapat digunakan sebagai usaha dalam pemberantasan Trematodosis pada kambing dalam rangka pengembangan peternakan kambing potong dan mengurangi jumlah kerugian yang ditimbulkan.

Trematodosis merupakan salah satu penyakit yang disebabkan oleh cacing dari kelas trematoda (Affroze dkk., 2013; Khedri dkk., 2015). Kejadian trematodosis dipengaruhi oleh banyak faktor antara lain inang, agen parasit, proses transmisi (perpindahan inang) dan lingkungan (Khan dkk., 2008). Munadi (2011) mengatakan bahwa penyebaran trematodosis juga dipengaruhi oleh faktor iklim, kelembaban dan faktor lain yang ada hubungannya dengan tatalaksana beternak termasuk rendahnya populasi siput sebagai inang perantara yang berpengaruh pada prevalensi trematodosis (Mubarok dkk., 2015). Prevalensi cacing trematoda pada musim hujan lebih besar karena ada kaitannya dengan ketersediaan air, vegetasi, dan kelembaban yang di perlukan oleh inang perantara dan metaserkaria untuk tumbuh dan berkembang (Karim dkk., 2015). Telur Paramphistomum cervi sulit ditemukan pada pemeriksaan feses karena bentuknya hampir sama dengan telur cacing Fasciola sp. dan penemuan cacing lebih mudah memiliki arti diagnostik dari pada penemuan telur yang masih perlu diidentifikasi lagi (Urquhart dkk., 2002).

Pemeriksaan diagnostik parasitosis pada hewan dapat dilakukan dengan pemeriksaan pasca mati, bila ada hospes mati atau sengaja dibunuh untuk keperluan diagnosis, cara ini sama seperti yang dilakukan untuk keperluan pemeriksaan daging, perbedaannya pada pemeriksaan parasit cacing lebih terarah dengan mencari cacing dewasa atau stadium larva, dengan demikian habitat cacing dewasa maupun larva perlu mendapat perhatian lebih cermat (Mumpuni dkk., 2016).

\section{Metode Penelitian}

Sampel berupa organ rumen dan retikulum yang diperoleh dengan bedah saluran pencernaan dari kambing kacang sejumlah 20 ekor dan kambing peranakan etawa sejumlah 16 ekor kemudian diberi label jenis hewan, dan tanggal pengambilan sampel. Rumen dan retikulum yang diambil dari RPH Pergirian Surabaya masing-masing dibuka atau dibedah dindingnya terlebih dahulu serta dengan mengeluarkan isinya untuk dibuang dengan perlahan. Dinding mukosa rumen dan retikulum lalu diperiksa, jika terdapat cacing di mukosa segera diambil dan dimasukkan ke dalam petridish yang berisi larutan $\mathrm{NaCl}$ fisiologis, beri label nama cacing dan spesies. Pewarnaan berfungsi agar memudahkan identifikasi dan untuk mengawetkan preparat cacing agar tahan lama. Pewarnaan cacing menggunakan metode Semichen-Acetic Camine yang mengacu pada Kuhlmann (2006). Cacing yang akan dibuat preparat dalam pewarnaan Semichen-Acetic Carmine ialah cacing segar maupun yang telah diawetkan dalam medium reservasi (Alkohol gliserin 5\%).

Cacing yang diperoleh dari koleksi rumen dan retikulum difiksasi di antara dua object glass dan diikat dengan benang, kemudian dimasukkan dalam alkohol gliserin $5 \%$ selama 24 jam. Setelah itu dilanjutkan dengan memasukkan ke dalam alkohol $70 \%$ selama 5 menit, dilanjutkan dengan memindahkan ke dalam larutan Carmine yang sudah diencerkan dan biarkan selama \pm 8 jam tergantung pada ketebalan kutikula cacing. Cacing dilepas dari fiksasi (object glass) dan dimasukkan ke dalam alkohol asam selama 2menit, selanjutnya dipindahkan ke dalam larutan alkohol basa selama 20 menit. Kemudian dilakukan dehidrasi bertingkat dengan alkohol, dimulai dari alkohol $70 \%$ selama 5 menit, alkohol $85 \%$ selama 5 menit, dan alkohol 95\% selama 5 menit, setelah itu dilanjutkan dengan mounting dalam larutan Hung's I selama 20 menit, cacing diambil dari larutan Hung's I dan diletakkan pada object glass yang bersih dan diteteskan larutan Hung's II secukupnya di atas cacing tersebut, dan ditutup dengan cover glass. Bagian terakhir yaitu preparat dikeringkan dalam inkubator suhu $37^{\circ} \mathrm{C}$, dilanjutkan didinginkan pada suhu ruangan. 


\section{Analisis Data}

Data yang diperoleh dianalisis dengan menggunakan rumus prevalensi untuk memperoleh angka prevalensi trematodosis rumen dan retikulum kambing. Prevalensi dihitung berdasarkan sampel +/ total sampel dinyatakan dalam $\%$.

Untuk mengetahui adanya perbedaan prevalensi infeksi cacing trematoda rumen dan retikulum pada kambing kacang dan kambing PE dilakukan analisis statistik dengan menggunakan Statistical Package for the Social Science (SPSS) 22.o for windows dengan menggunakan metode Chi-Square Test.

\section{Hasil dan Pembahasan}

Berdasarkan hasil pemriksaan yang dilaksanakan pada 36 sampel rumen dan retikulum kambing yang dipotong di RPH Pegirian selama bulan September hingga November 2017, didapatkan jenis cacing yang seluruhnya dari kelas Trematoda yaitu Paramphistomum cervi dan Cotylophoron cotylophorum.

Identifikasi sampel positif $P$. cervi dan $C$. cotylophorum pada rumen menggunakan metode bedah saluran pencernaan dan kunci identifikasi menggunakan Soulsby (1986).

Pada cacing Paramphistomum cervi terdapat genital pore sedangkan pada cacing Cotylophoron cotylophorum tidak terdapat genital pore melainkan oesophagus yang bercabang dan terdapat kelenjar vitelin. Cacing paramphistomum cervi memiliki ciri terdapat oral sucker, genital pore, uterus, testis, ventral sucker. Gambar cacing Paramphistomum cervi dapat dilihat pada Gambar 1.

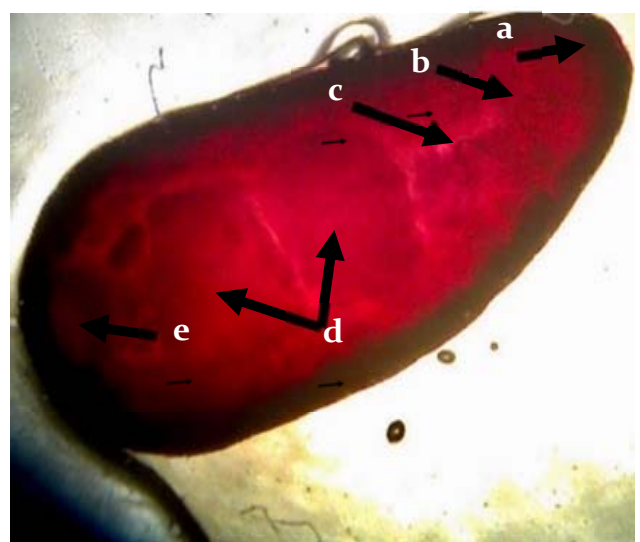

Gambar 1. Cacing Paramphistomum cervi (20x). Mikroskop Dissecting. (a) Oral sucker, (b) Genital pore, (c) Uterus, (d) Testis, (e) Ventral sucker.
Pada cacing Cotylophoron cotylophorum memiliki ciri terdapat oral sucker, oesophagus bercabang, uterus, kelenjar vitelin, testis dan posterior sucker . Cacing C. cotylophorum dapat dilihat pada Gambar 2.

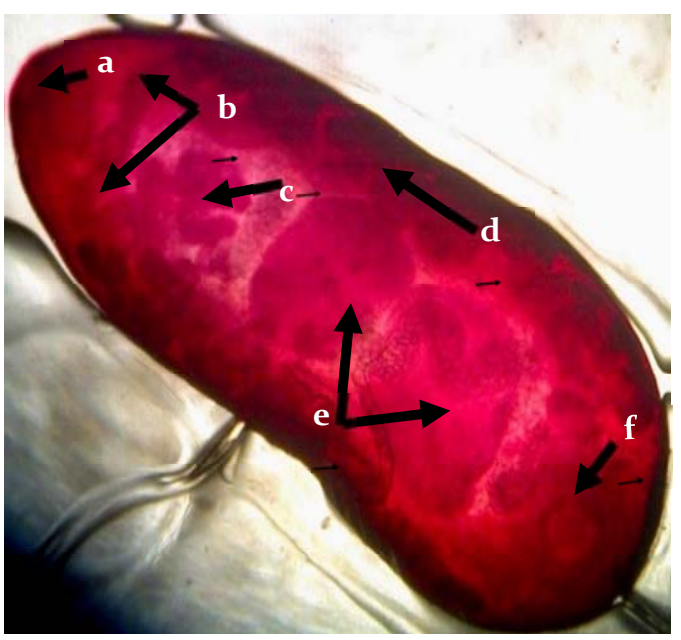

Gambar 2. Cacing Cotylophoron cotylophorum (20x). Mikroskop Dissecting. (a) Oral sucker, (b) Oesophagus bercabang, (c) Uterus, (d) Kelenjar vitelin, (e) Testis, (f) Posterior sucker.

Berdasarkan pemeriksaan laboratorium dengan menggunakan metode bedah saluran pencernaan terhadap 36 rumen dan retikulum dari RPH Pegirian Surabaya, 3 rumen dinyatakan positif didapatkan cacing trematoda dengan prevalensi sebesar 8,33\%, Hasil penelitian seperti terlihat pada Tabel 1 .

Tabel 1. Prevalensi Cacing Pada Rumen Kambing di RPH Pegirian Surabaya

\begin{tabular}{cc}
\hline Hasil & Jumlah Kambing \\
\hline Positif & $3(8,33 \%)$ \\
Negatif & $33(91,67 \%)$ \\
\hline Total Sampel & $36(100 \%)$
\end{tabular}

Pengambilan 36 rumen dan retikulum kambing yang terdiri dari 20 kambing kacang dan 16 kambing peranakan etawa, didapatkan hasil positif dengan ditemukan cacing $P$. cervi dan $C$. cotylophorim, pada kambing kacang posistif 2 kambing (10\%), sedangkan pada kambing peranakan etawa positif ditemukan cacing $P$. cervi dan $C$. cotylophorum sebanyak 1 kambing $(6,25 \%)$. Hasil penelitian dapat dilihat pada Tabel 2. 
Tabel 2. Prevalensi Cacing Pada Rumen Berdasarkan Jenis Kambing di RPH Pegirian Surabaya.

\begin{tabular}{cccc}
\hline Jenis & \multicolumn{2}{c}{ Hasil Pemeriksaan } & Total \\
Kambing & Positif & Negatif & Sampel \\
\hline $\begin{array}{c}\text { Kambing } \\
\text { Kacang }\end{array}$ & $2(10 \%)$ & $18(90 \%)$ & 20 \\
Kambing PE & 1 & 15 & 16 \\
\hline
\end{tabular}

Hasil uji analisis statistik menggunakan chi-square test menunjukan nilai $(\mathrm{p}=1,000)$. $\mathrm{p}>0,05$ yang berarti hasil tidak signifikan maka hipotesis tidak diterima, yang berarti tidak terdapat pengaruh ras kambing terhadap infeksi cacing trematoda pada rumen dan retikulum kambing yang dipotong di RPH Pegirian Surabaya.

Sampel yang digunakan yaitu 36 rumen dan retikulum kambing yang berasal dari RPH Pegirian Surabaya kemudian diperiksa menggunakan metode bedah saluran pencernaan di Laboratorium Departemen Parasitologi untuk menemukan cacing Paramphistomum cervi dan Cotylophoron cotylophorum. Hasil pemeriksaan terdapat 3 kambing positif Trematodosis dengan prevalensi $8,33 \%$.

Hasil identifikasi cacing Paramphistomum cervi dan Cotylophoron cotylophorum yang dilihat menggunakan mikroskop menunjukan bahwa kedua cacing hemaprodit, testis sedikit berlobi dan terletak tendem sebelah anterior ovarium. Sesuai dengan pernyataan dari Soulsby (1982), cacing $P$. cervi terdapat genital pore sedangkan pada cacing $C$. cotylophorum tidak terdapat genital pore melainkan oesophagus yang bercabang dan terdapat kelenjar vitelin.

Berdasarkan analisis Chi Square Test menunjukkan hasil yang tidak signifikan $(\mathrm{p}>0,05)$ dengan nilai $\mathrm{p}=1,000$ yang berarti tidak terdapat pengaruh ras kambing terhadap infeksi cacing trematoda pada rumen dan retikulum kambing yang dipotong di RPH Pegirian Surabaya. Semua ras kambing bisa terinfeksi cacing trematoda, kemungkinan karena sistem imun kambing dan lingkungan disekitar kambing sudah terkontaminasi larva infektif. Sesuai dengan pernyataan dari Melaku dan Addis (2012) bahwa infeksi Paramphistomiasis pada ternak akan lebih tinggi kejadiannya pada ternak dengan imunitas yang rendah. Faktor lingkungan yang mempengaruhi siklus hidup cacing yaitu, inang perantara, kelembaban, suhu dan frekuensi hujan (Soulsby, 1982). Diperkuat oleh pernyataan dari Beriajaya (1986) dan Endi
(1985) Trematodosis pada musim penghujan lebih tinggi dari pada musim kemarau karena musim penghujan merupakan lingkungan yang cocok bagi perkembangan telur cacing.

Penelitian ini menunjukkan prevalensi yang rendah $(8,33 \%)$ dari penelitian yang dilakukan Godara dkk., (2014) dengan prevalensi $30,9 \%$ Hal tersebut dimungkinkan karena kambing yang dipotong di RPH Pegirian Surabaya sistem pemeliharaan dan sanitasi kandang dilakukan dengan baik oleh peternak. Menurut Subronto (2007) sanitasi, sistem pemeliharaan, pakan dan pengobatan mempengaruhi tingkat trematodosis. Efektivitas pemberian antelmintik dipengaruhi oleh ketepatan dosis, sprektrum antelmintik, dan cara pemberian (Pfukenyi dkk., 2006).

Cacing trematoda positif pada 3 kambing yang dipotong di RPH Pegirian Surabaya, dimungkinkan karena ternak digembalakan dan pakan yang diberikan oleh peternak mengandung metaserkaria. Ternak yang digembalakan kemungkinan berkaitan dengan tingginya tingkat kontaminasi lapangan penggembalaan yang terdapat siput sebagai inang perantara, kurangnya tindakan pengendalian, dan kurangnya pengetahuan dari peternak (Melaku dan Addis,. 2012).

Infeksi cacing saluran pencernaan yang merupakan parasit patogenik dapat berasal dari rumput di padang penggembalaan dan pakan hijauan terutama pada musim hujan, untuk menghindari kambing terkena cacingan maka pemilik kambing harus lebih memperhatikan pakan ternak dengan menghindarkan makanan seperti rumput yang masih terkena tanah basah (Basri, 2012).

\section{Kesimpulan}

Jenis cacing yang ditemukan pada penelitian ini seluruhnya dari kelas Trematoda spesies $P$. cervi dan Cotylophoron cotylophorum. Prevalensi Trematodosis pada kambing yang di potong di RPH Pegirian Surabaya sebesar 8,33\%. Analisis menggunakan chi-square menunjukkan bahwa tidak terdapat pengaruh ras kambing terhadap infeksi cacing trematoda.

\section{Daftar Pustaka}

Abunza, M., Ahmad, A and Afana, S. 2008. Prevalence and Paramphistomiasis in Ruminants Slaughtered at Soko Cental Abattoir, Sokoto. Nigeria Journal of Basic and Applied Sciences. Vol. 16. No.2:287-292. 
Affroze, S., Begum N, Islam MS, Rony SA, Islam MA, Mondal MMH. 2013. Risk Factors and Gross Pathology of Bovine Liver Fluke Infection at Netrokona District, Bangladesh.J Anim Sci Adv 3(2):83-90.

Beriajaya,. 2005, 'Gastrointestinal Nematode Infections on Sheep and Goats in West Java Indonesia', Jurnal Ilmu Ternak dan Veteriner, vol. 10, no.4, hal 293-304

Basri, E., Prabowo, A., and Firdaus, A. 2012. Infeksi Cacing Saluran Pencernaan Kambing Peranakan Etawa (PE) Milik Petani Kakao di Kecamatan Kedondong, Kabupatn Pesawaran. Prosiding Seminar Nasional Sains dan Inovasi Teknologi Pertanian. 523-531.

Endi, S.1985. Tinjauan Masalah Infestasi Haemonchus contortus (Rudolphi,1803)n pada Domba di Indonesia. Skripsi. Fakultas Kedokteran Hewan. Institut Pertanian Bogor. Bogor.36.

Godara, R. Katoch, R and Yadav, A. 2014. Epidemiology of Paramphistomosis in Sheep and Goats in Jammu, India. J Parasit. $38(4): 423-428$.

Junquera, 2017. Paramphistomum spp. Rumen Flukes Parasities of Cattle Sheep Goats and Other Livestock Biology Prevention and Control.

Karim, M., Parvin, M and Hossain, M. 2014. A Report on Clinical Prevalence of Disease and Disoders in Cattle and Goats at The Upazilia Veterinary Hospital, Mohammad pur, Magura Balangdesh. Bang. J.Vet. Med. 12(1): 47-53.

Karim, MR., Mahmud MS, Giasuddin M. 2015. Epidemiological Study of Bovine Fasciolosis: Prevalence and Risk Factor Assessment at Shahjadpur Upazila of Bangladesh. Immunol Infect Dis. 3(3):2529.

Khan, UJ., Tanveer A, Maqbool A, Masood S. 2008. Epidemiological Studies of Paramphistomosis in Cattle. Vet Arhiv. 78(3):243-251.

Khedri, J., Radfar MH, Borji H, Mirzaei M. 2015. Prevalence and Intensity of Paramphistomum spp. In Cattle from South -Eastern Iran. Iran J Parasitol. 10(2):268-272.
Koesdarto, S., S. Subekti., S. Mumpuni., H. Puspitawati dan Kusnoto. 2007. Buku Ajar Ilmu Penyakit Nematoda Veteriner. hal. 2326.

Kusumamiharja, S. 1995. Parasit dan Parasitosis pada Hewan dan Hewan Piara di Indonesia. Bogor. : PAU Bioteknologi IPB. 121.

Melaku, S., Addis M. 2012. Prevalence and Intensity of Paramphistomum in Ruminants Slaughtered at Debre Zeit Industrial Abattoir, Ethiopia. Glob Vet. (8)3: 315-319.

Mubarok, S., Suratma NA, Dwinata IM. 2015. Prevalensi Trematoda di Sentra Pembibitan Sapi Bali Desa Sobangan, Kecamatan mengwi, Kabupaten Badung. Ind Med Vet. $4(1): 48-53$.

Mumpuni, S., Subekti, S., Koesdarto, S., Puspitawati, H., dan Kusnoto. 2016. Penuntun Praktikum Ilmu Penyakit Helminth Veteriner. Fakultas Kedokteran Hewan Universitas Airlangga. Surabaya. hlm. 1.

Munadi. 2011. Tingkat Infeksi Cacing Hati Kaitannya dengan Kerugian Ekonomi Sapi Potong yang Disembelih di Rumah Potong Hewan Wilayah Eks Karesidenan Banyumas. Agripet 11(1):45-50.

Pfukenyi, D.M, Mukaratirwa, S,. Willingham A.L, Monrad J. 2006. Epidemiological studies of Fasciola Gigantica Infections in Cattle in The Highveld and Lowveld Communal Grazing Areas of Zimbabwe. Onderstepoort J Vet Res. 73: 37-51.

Shabih, H. and Juyal, P. Epidemiological Observations of Paramphistomiasis in Ruminants in Endemic Regions of Punjab and Adjoining State, India. Proceedings of the 11th International Symposium on Veterinary Epidemiology and Economic. (1):1-6.

Subronto, 2007. Ilmu Penyakit Ternak II. Gajah Mada University Press. Yogyakarta. Hal: 64109.

Soulsby, EJ.L. 1982. Helminth, Artrhopods and Protozoa of Domesticated Animals. New York an London, Academic Press. 66-68.

Soulsby, EJL,. 1986. Helminth, Arthropods and Protozoa of Domecticated Animals. Ed ke7. London: Bailliere Tidall. 214-243. 
Tehrani, A., Javanbakht, J. And Khani, F. 2013. Prevalence and Pathological Study of Paramphistomum Infection in The Small Intestine Of Slaughtened Ovine. J Parasit Dis 39(1):100-106.
Urquhart, M.G., J. Armour, J.L. Duncan, A.M. Dunn and F.W. Jenning. 1988. Veterinary Parasitology. English Language Book Society. Longman. 227-231. 